\title{
Unconventional exhibition spaces as an example of the synergy of architecture and art
}

\author{
Paulina Kowalczyk \\ https://orcid.org/0000-0003-2244-4860 \\ paulina.kowalczyk@put.poznan.pl \\ Institute of Architecture, Urban Planning and Heritage Protection, Faculty of Architecture, \\ Poznań University of Technology
}

\section{Joanna Stefańska}

http://orcid.org/0000-0003-0080-9072

joanna.stefanska@put.poznan.pl

Institute of Architecture and Interior Design, Faculty of Architecture, Poznań University of Technology

\author{
Agata Gawlak \\ https://orcid.org/0000-0002-6234-7953 \\ agata.gawlak@put.poznan.pl
}

Institute of Architecture, Urban Planning and Preservation, Faculty of Architecture, Poznań University of Technology

\begin{abstract}
Summary: The article pertains to the relationship between an artwork (painting) and architectural space, as well as the issue of adapting unconventional architectural spaces for an exhibition function in relation to the author's exhibitions presenting the paintings from the same painting series. Different exhibition concepts of each of the exhibitions emphasize the role of a painting in shaping the architectural space and the quality of this space. An artwork becomes a tool that organizes space and influences its quality.

At the Faculty of Architecture of Poznan University of Technology, as part of the research project of Professor A.M. Łubowski and J. Stefańska, D.Sc., titled "Artwork in Architecture", there has been research conducted on the correlation of architecture and art. The author was invited to participate in three exhibitions carried out as part of this project. The experiences connected with the project have been described in this article.

The problem of using the interiors of buildings whose original purpose was different from exhibiting art, became a part of the author's research carried out in the form of individual and collective exhibitions. Two of them, which took place between 2017 and 2018, showcased paintings from the same series, entitled "I Have Been to Hel(I) and Back. And: Let me Tell you, It Was Wonderful", highlighted the importance of the dialogue between architecture and art and created awareness how much this interdependence influences the transformation of the perception of both art and architecture. Appropriate compositional solutions and an appropriate selection of artworks contribute to the complete visual satisfaction of the recipient. III-considered combinations cause visual discomfort, which detracts from the potential of both works of art and architectural space. Therefore, it is a need to perform an in-depth analysis of the relationship between the artwork and architectural space, and to avoid conventional, schematic exhibition solutions.

The same works placed in various spaces affect the viewer in a different way. The change of the environment influences the change of perception, which creates new interpretative possibilities for the painting's narrative, while the architectural space gains a wider context of reception through its individualization and increased accessibility. The emotional and intellectual aspect of painting enriches the space with new meanings.
\end{abstract}

Keywords: unconventional spaces, exhibition space, architecture, art 


\section{Introduction}

The classic vision of an ideal exhibition space assumes subordinating the space to artworks. Such a place is far from being individualized. It is often a "white cube" - an evenly lit room with white walls, built on a square or rectangular plan, deprived of divisions. Spaces made of non-obvious divisions, incorporating the play of light, planes, and the richness of textures create new opportunities for the exhibition of art objects. In such interiors, a dialogue between artworks and space may initiate unconventional exhibition projects. Paintings placed in architectural space do not only fulfil a decorative function - they become elements shaping and individualizing the space. The mutual relationship between the work of art and the exhibition space is worth exploring and defining. In particular, an attempt to consciously shape relationship of contrast or subordination between the artwork (object) and the background (spatial context), make it possible to control the attention of the recipient and his movement (analogous to research in the area of landscape \& townscape perception).

Introducing an exhibition function to a building intended for a primary purpose other than exhibiting art may increase the legibility of the functional layout, the availability of space and its social role. Conscious arrangement and composition activities as well as the quality of art objects can shape the perception of space in a surprising way, same as the exhibition space can influence the painting narrative by transforming the picture - background relationship.

Shaping the architectural space by adding an exhibition function introduces an emotional factor that has a transformative potential. An emotionally neutral space can gain an additional value - previously ignored forms and structures, in a new context, often gain meaning, becoming equivalent components of architectural space. Objects of art placed in architectural space also gain new reception and, finally, potential interpretations. The architectural space is a continuum of the painting narrative. All forms interact with each other - both the painted and the real ones. Appropriate implementation of painting works into architectural spaces of buildings increases the satisfaction of its users of the space.

\section{Implementation of exhibition concepts as part of analyzing the relationship between painting and architectural space}

In 2018, at Gallery 33 in Ostrów Wielkopolski, an individual exhibition of the artist's paintings titled "Traces" was held. The exhibition space is a granary adapted to the needs of an art gallery in 2012 on the initiative of Krzysztof Ryfa, an artist from Ostrów Wielkopolski. The paintings have been carefully selected to suit the character of the architectural space. The interior divisions, proportions, as well as specific light and colours became the main inspiration when choosing the paintings. Moreover, the specificity of the place evoked the creation of several canvases referring to the character of this space. The author of the exhibition decided to keep the existing colours of the walls. The division into the white (light) and black (dark) zones significantly influenced the exhibition arrangement. Value contrasts in painting and colours had their continuum in the architectural space. The relationships between individual paintings and the decision to maintain the rhythm determined by the squares of the canvases in appropriate scales - significantly influenced the perception of space. The paintings, displayed on white or black walls respectively, were in some way merged with the background by blurring the border between the canvas, which gained the painting narrative an optical, illusory continuum in the surrounding space. The background has become an important part of the paintings. The division into an art object and its surroundings is no longer obvious. One has become a part of the other. The transformation of the architectural space as well as the paintings placed, took place on many levels. The aforementioned rhythms created by the canvases, as well as those determined by the construction structure of the granary, the colour relations between the architectural and painting elements, as well as the natural light used during the vernissage, and the brightness of the colours used in the paintings, created an intriguing, surprising play of similarities and differences. The interior of the former granary with its mysterious, dimmed light, forced the original concept of the exhibition to change. Strong contrasts and simplified, organic or geometric forms in the paintings correlated with the dynamics of daylight were equally intense and created forms similar to the ones in the paintings. The reds used on the canvases, intensified by the addition of neon paint, introduced an element 
of surprise to the architectural space in the form of a colour contrast. The dynamics of the colour itself, as well as dissimilar colouring in the context of the surroundings, made the perception of space even more dynamic.

"The relations between the elements of the perceptual field are hardly ever (if ever) as simple as the associating models used in traditional theories suggest (...).The relationship in question affects the related elements, but often modifies them significantly. As with similarity, so is the contrast (...). Confrontation can bring out, emphasize and purify certain features." (Rudolf Arnheim, Visual Thinking pp. 75-76).

The exhibition, viewed in natural and artificial light, has shown how important a factor light is in creating reality. Its variability created two exhibition variants revealing a new potential of both architectural space and paintings.
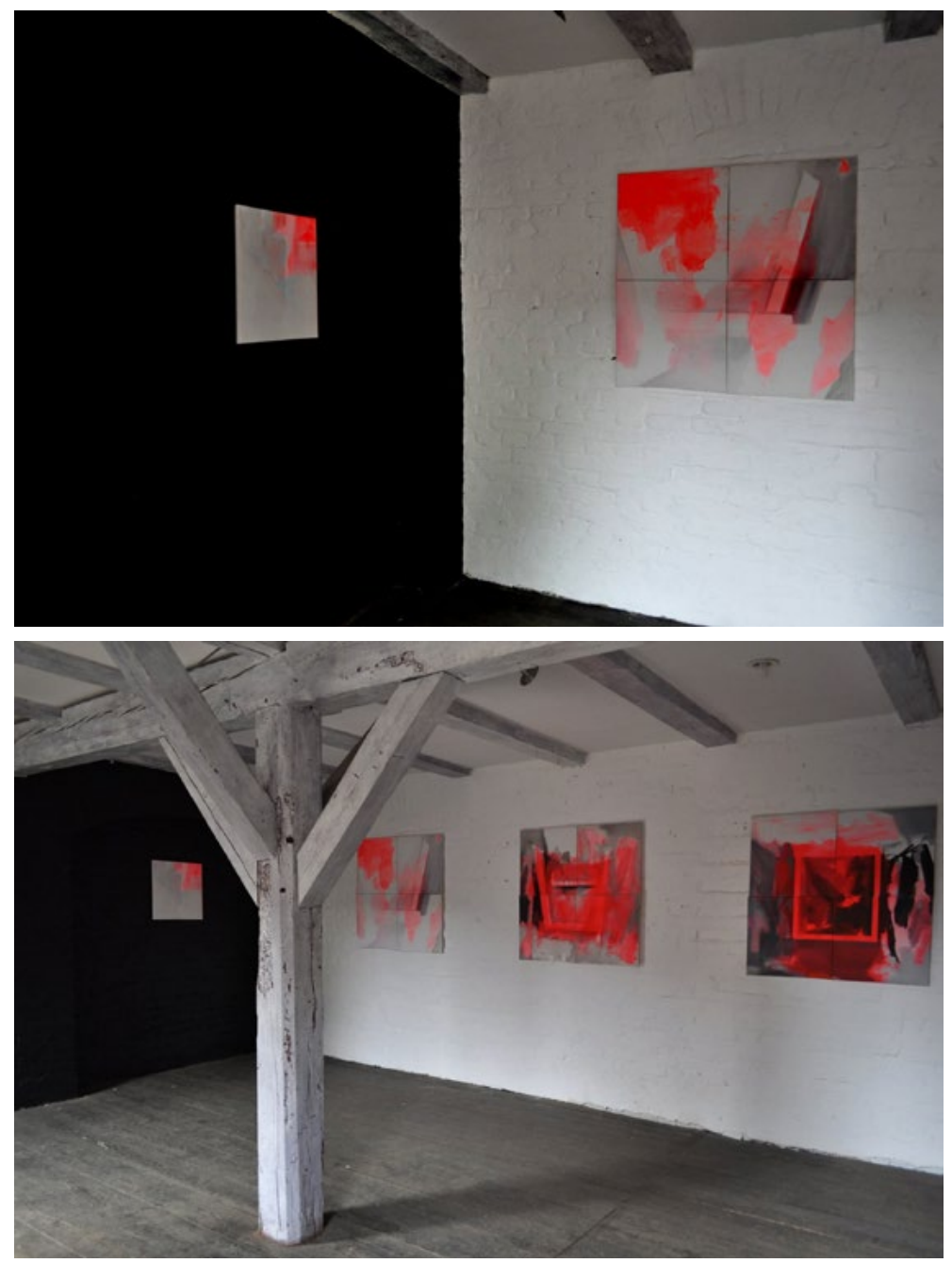

Fig. 1., 2. Parts of the exhibition in Gallery 33 in Ostrów Wlkp. - visible division into light and shadow zones; the game of differences and similarities between the paintings and the exhibition space. Author of the photos: Paulina Kowalczyk

Several works from the series presented at Gallery 33 were also shown in Lubanta Gallery in Lubon at the collective exhibition entitled "Spaces II", which was part of the research project of J. Stefańska, D.Sc., and Professor A.M. Łubowski. Visual artists, associated with the Faculty of Architecture of Poznań University of Technology, the University of the Arts Poznań, and The Szczecin Art Academy participated in the exhibition. The gallery in Lubon is an example of a successful adaptation of a part of a post-industrial building, a former potato industry plant, Lubanta S.A., for a very unusual exhibition space. The red brick building, concealing a wealth of materials, colours, textures, and surprising design solutions, has become an ideal place to display art objects from various disciplines. The similarities and differences between the individual works became part of the dialogue with the architectural space. 


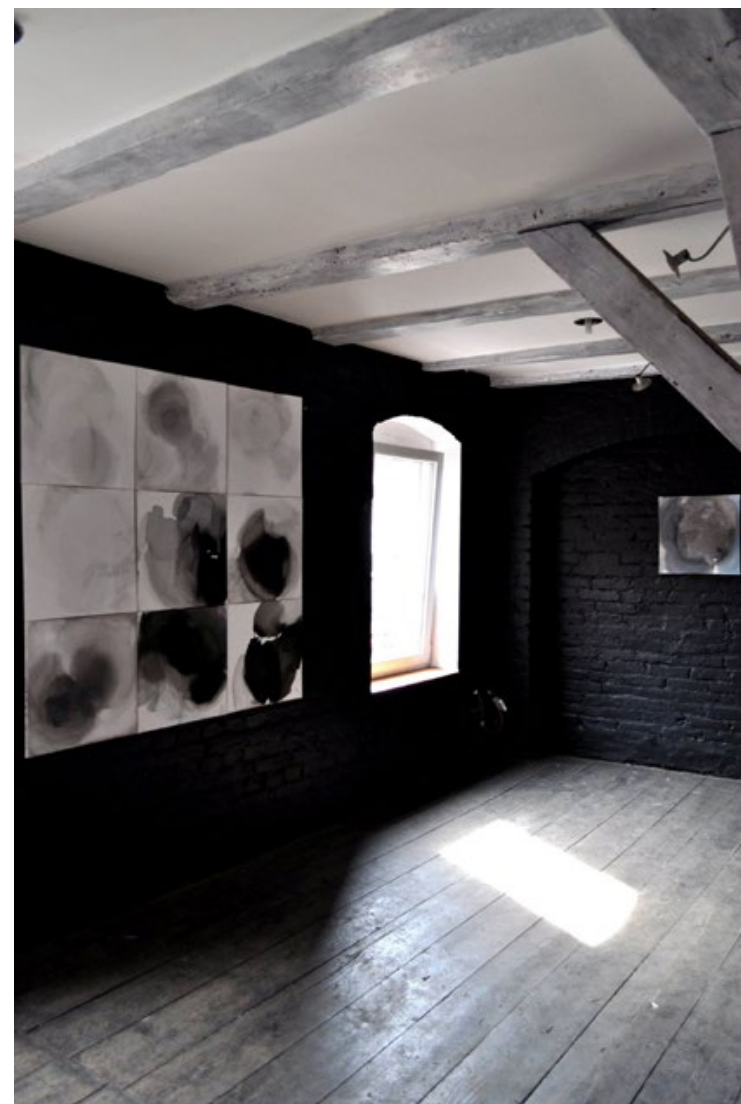

Fig. 3. Light as a factor creating physical and painting reality - a record of the relationship between sunlight and light in painting; an attempt to find a correlation. Author of the photo: Paulina Kowalczyk

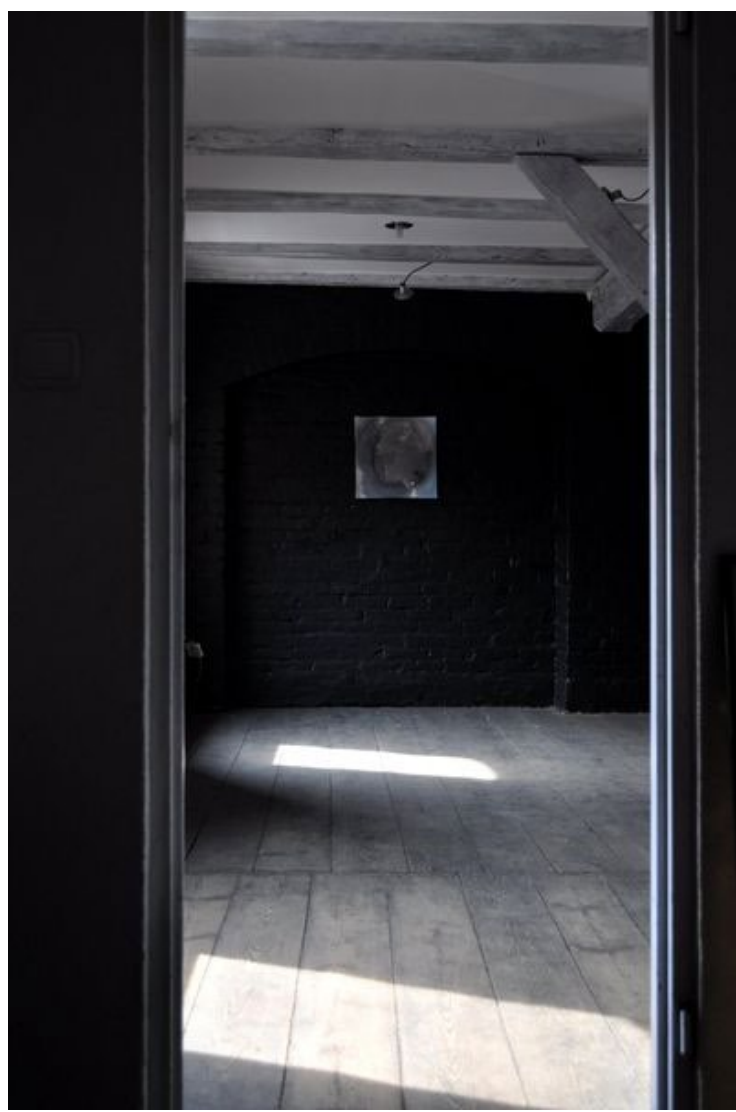

Fig. 4. The play of light and forms in the architectural space and the space of the painting. Author of the photo: Paulina Kowalczyk

The author's paintings, through the colour reference to the building's facade, highlighted the relationship between the interior and the exterior. The works were hung on a gray, semi-circular wall, partially covered with sheet metal. The decision to use a colour contrast between the canvases and their background influenced the radical selection of canvases intended for the exhibition in Lubanta. The works of other artists participating in the exhibition adjacent to these paintings were also important. The relationship between art objects created additional tensions, building a multi-faceted dialogue between architecture and art. The dependencies and interactions showed the new potential of the space itself, as well as the works shown at the exhibition. The unconventional space forced non-obvious, often very risky exhibition decisions. In the case of the author's paintings, it was a decision related to the use of the play of light visible on the metal sheets that were part of the walls, which constituted the background for the presented painting. The sheet metal reflections became a continuum of the painting content, supplementing it with new perceptual and interpretation variants and introducing an additional element dynamising the composition.

A complementary value was the opportunity to use both daylight and artificial light, which resulted in a complete change in the reception of the works. The mysterious twilight favoured the concentric use of light, which created additional divisions into the exhibition zones in the interior. "Even, bright light paralyzes the imagination in a way in which homogenization of space weakens the experience of being and erases the sense of a specific place. The human eye is almost perfectly tuned to perceive twilight, not bright light. " (Juhani Pallasmaa, The Eyes of the Skin, p. 58). An intense stream of light directed at the canvases, exposing the painting dramaturgy by exposing or even deepening the contrasts and intensifying the reds covering the presented canvases. 

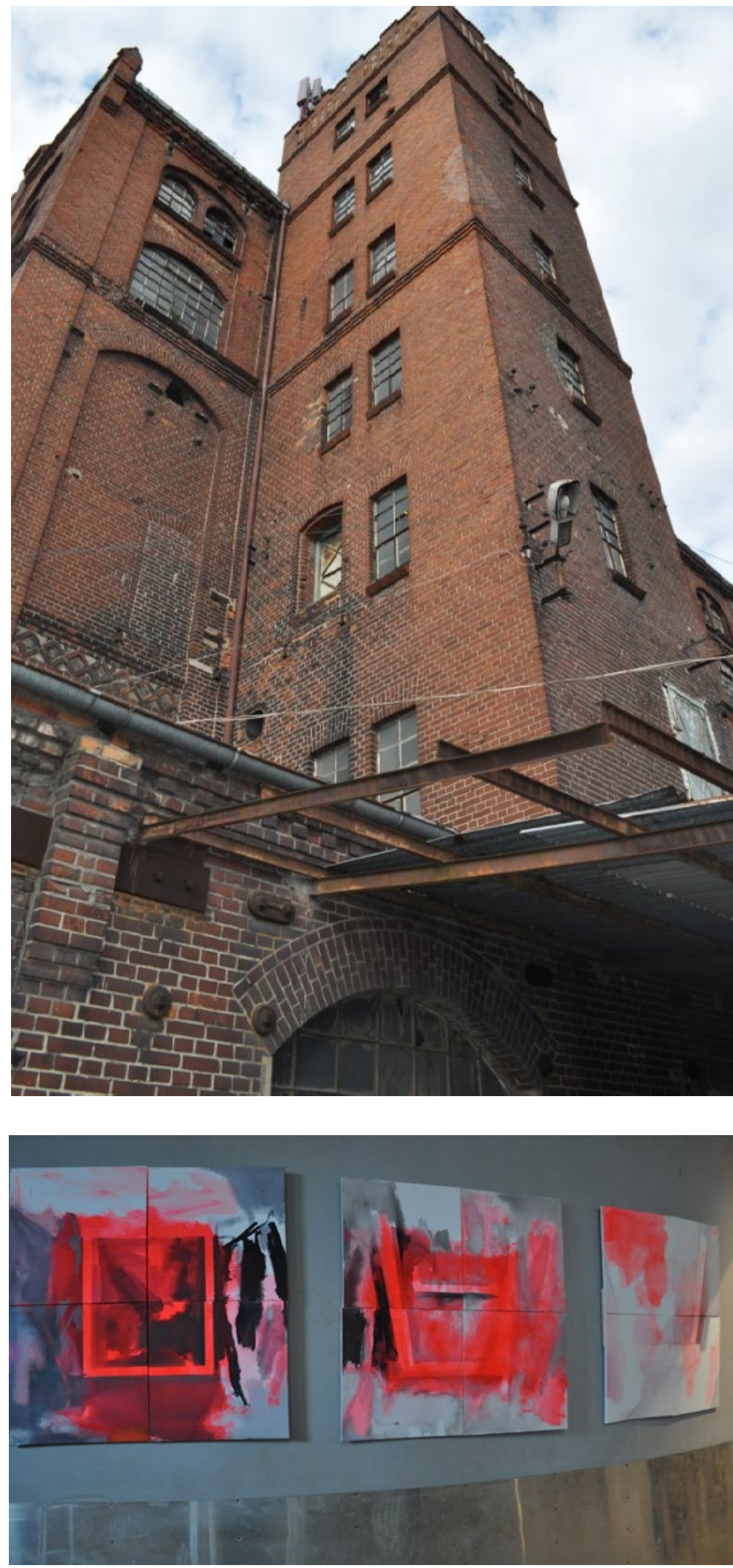

Fig. 5. Part of the facade of the Lubanta S.A. building in Lubon', where the exhibition entitled "Spaces II" took place. Author of the photo: Paulina Kowalczyk

Fig. 6. Part of the exhibition "Spaces II" in natural light - paintings by Paulina Kowalczyk (three canvases measuring $100 \times 100 \mathrm{~cm}$, in mixed technique from the series "I Have Been To Hel(I)..." Photo by: Paulina Kowalczyk 

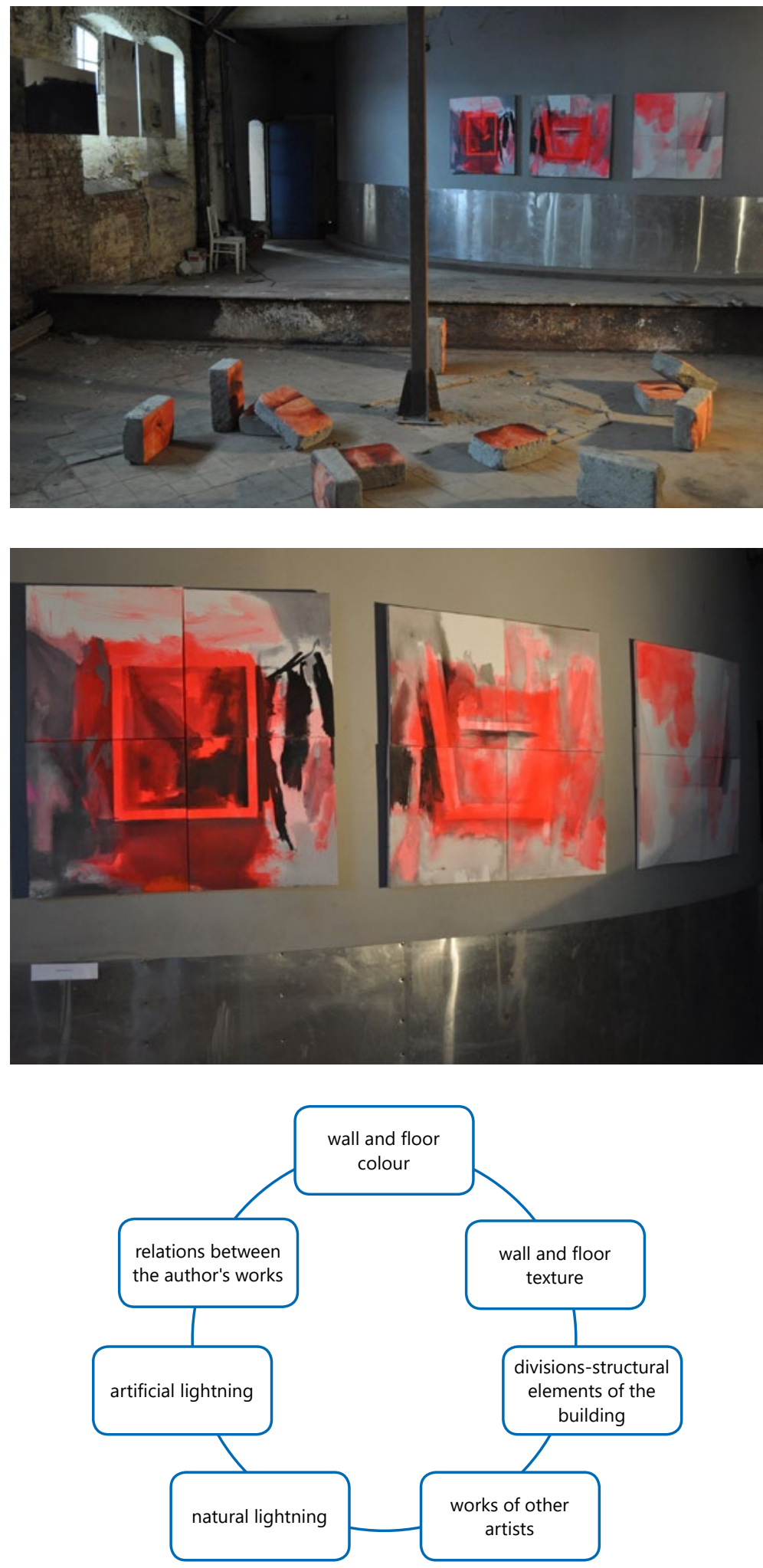

Fig. 7. Part of the exhibition "Spaces II" in Lubanta Gallery in Luboń in natural lighting. On the left, paintings by Joanna Stefańska, in the foreground, paintings by Andrzej Maciej Łubowski. Author of the photo: Paulina Kowalczyk

Fig. 8. Paintings exposed in artificial light - the use of an additional light source to intensify the value contrast, colour saturation and reflections on the sheet metal ( visible warming of colours and greater luminosity of neon pigments). Author of the photo: Paulina Kowalczyk

Fig. 9. Features of the exhibition space that have become an integral part of the work during the exhibition 


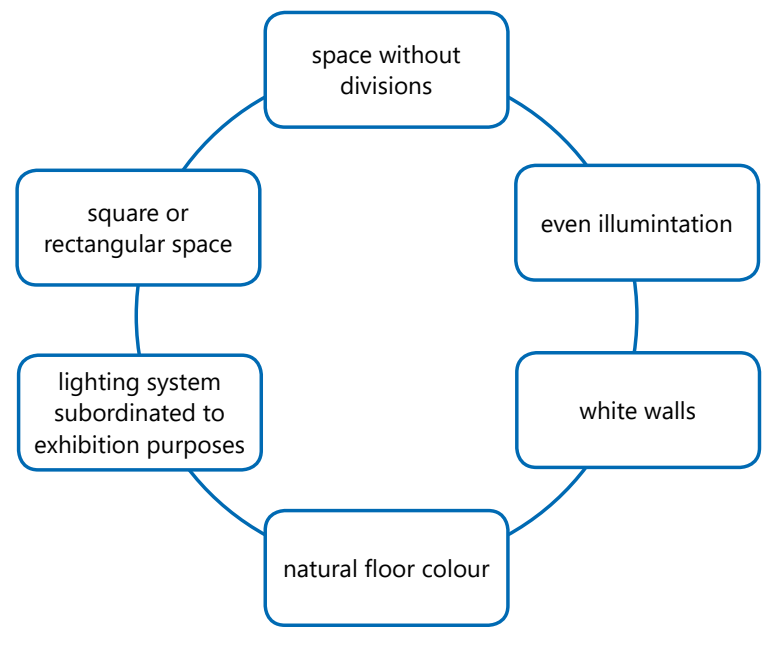

Fig. 10. Features of the "White Cube" exhibition space

\section{Conclusions}

The coexistence of architecture and art is based on dialogue. Correlations make it possible to change the perception of both architectural space and the objects of art placed in it. Interactions between the individual components of a given space, which also become paintings during the exhibition, build a new perceptual quality. The painterly narrative is extended in the architectural space, which absorbs the emotional and intellectual dimension of art objects and gains additional aesthetic values. Art individualizes architectural space. In addition, the utility function of an architectural object enriched with an exhibition function receives an additional attribute in the form of wider public accessibility. The same paintings presented in various interiors, often far removed from the exhibition concept of "white cube", acquire a heterogeneous character. The perceptual transformation of works and architectural space shows how much the relationship between art objects and an architectural object can become a factor creating adaptive possibilities of architectural space.

The composition in paintings, their dynamics, forms and colours impose a new character on the architectural space, just as the architectural space influences the painting content. On the other hand, the painting narrative exposes the often non-obvious values of architectural space and increases its individualisation. Architectural and painting forms interact synergistically. The exhibition arrangement may emphasize the differences between the character of the art object and the architectural space, or be based on similarities. Depending on the situation, the planned effect, the correlations between painting and the interior can be dynamic or based on full harmony, sometimes close to mimetism.

The relationship between an artwork, architectural space and the recipient shows the importance of analyzing the specificity of the place and the exhibition concept. The multifaceted nature of exhibition problems provokes reflection and draws attention to the need to look for alternative solutions for annexing architectural space to the requirements of art exhibition.

\section{Summary}

Architecture and art are in a constant dialogue. The transformation of the interior and the painting content takes place simultaneously.

Architectural space that annexes art objects as elements that enrich perception and increase the availability of architectural objects whose original function did not involve exhibition, opens the architectural object to new recipients and enhances the sensual perception of architecture. The aesthetic and intellectual aspect of painting enriches the architecture with additional content, which, in the case of successful exhibition projects, means increasing the prestige of the building itself. As Juhani Pallasmaa wrote: "Art designs an unattainable ideal - an ideal of beauty that touches eternity for a moment." ("The Eyes of the Skin: Architecture and the Senses", p. 66). 
Painting works placed in a specific space are also a subject to perceptual metamorphosis. The interdependence of architecture and art means the possibility of creating a new perception and discovering a new potential of both architectural space and art objects.

\section{Bibliography}

[1] Arnheim, R., 1978, Sztuka i percepcja wzrokowa. Psychologia twórczego oka, Warszawa

[2] Arnheim, Rudolf .1966. Towards Psychology of Art. University of California Press, Berkley an Los Angeles.

[3] Arnheim, Rudolf . 1969. Visual thinking.The Regents of the University of California. Renewed 1997

[4] Łubowski, A.M „, J. Stefańska, 2019. Przestrzenie. Dzieło plastyczne w architekturze. Wydawnictwo Politechniki Poznańskiej, Poznań

[5] Łubowski, A.M „ J. Stefańska, 2020. Relacje. Dzieło plastyczne w architekturze. Wydawnictwo Politechniki Poznańskiej, Poznań

[6] Pallasmaa, J., 2012. Oczy skóry: Architektura i zmysły, Instytut Architektury, Kraków

[7] Pallasmaa, J, 2005 The Eyes of the Skin: Architecture and the senses, John Wiley \& Sons Ltd, Great Britain 